\title{
Synthesis of High-Purity $\mathrm{SnO}_{2}$ Nanobelts by Using Exothermic Reaction
}

\author{
Guodong Zhang, Nian Liu, Zhengyuan Ren, and Bing Yang \\ Department of Materials Engineering, Center for Electron Microscopy, Wuhan University, Wuhan 430072, China \\ Correspondence should be addressed to Guodong Zhang, guo_dong_zhang@126.com
}

Received 20 January 2011; Accepted 27 March 2011

Academic Editor: Gong Ru Lin

Copyright () 2011 Guodong Zhang et al. This is an open access article distributed under the Creative Commons Attribution License, which permits unrestricted use, distribution, and reproduction in any medium, provided the original work is properly cited.

\begin{abstract}
This paper presents a new method to synthesize high-purity single-crystalline $\mathrm{SnO}_{2}$ nanobelts with rutile structure. The purity, morphology, crystal structure, and sizes of the as-grown $\mathrm{SnO}_{2}$ nanobelts are characterized by X-ray diffraction, energy-dispersive $\mathrm{X}$-ray analysis, scanning electron microscopy, transmission electron microscopy, and Raman-scattering spectroscopy. The scanning electron microscopy and transmission electron microscopy reveal tetragonal $\mathrm{SnO}_{2}$ nanobelts of 50-120 nm in width, 20-50 nm in thickness, and 2-10 $\mu \mathrm{m}$ in length. The three observed Raman peaks at 475, 633, and $774 \mathrm{~cm}^{-1}$ indicate the typical rutile structure of the $\mathrm{SnO}_{2}$, which is in agreement with the X-ray diffraction results, and other peaks of impurity are not found. High-resolution transmission electron microscopy demonstrates that the nanobelts have a high degree of crystallinity, without typical imperfects in it. And the growth mechanism of the $\mathrm{SnO}_{2}$ nanobelts is discussed.
\end{abstract}

\section{Introduction}

In recent years, one-dimensional nanostructures, such as nanorods, nanowires, and nanobelts, have attracted considerable attention in the field of material, because of their peculiar structure characteristics and size effects $[1,2]$. In fact, different kinds of one-dimensional nanostructures with different materials $\left(\mathrm{SnO}_{2}, \mathrm{ZnO}, \mathrm{PbO}_{2}, \mathrm{In}_{2} \mathrm{O}_{3}, \mathrm{CdS}\right.$, $\mathrm{MgO}$, etc.) have been successfully synthesized [2-5]. Among these materials, one-dimensional nano- $\mathrm{SnO}_{2}$ with rutile structure, as an n-type semiconductor with a wide bandgap ( $\mathrm{Eg}=3.6 \mathrm{eV}$ at room temperature), is well known for its excellent gas sensitivity and electrical properties. According to earlier reporters $[2,6-11]$, one-dimensional nano- $\mathrm{SnO}_{2}$ is synthesized by a variety of methods, such as hydrothermal process, thermal evaporation, chemical vapor deposition (CVD), physical vapor deposition (PVD), laser ablation technique, carbothermal reduction, and calcination process. However, all of these methods are hard to be widely used due to either their high requirements for experimental equipments or the complexity of processes.

This paper presents a new method, namely, the exothermic reaction synthesis (ERS), to synthesize high-purity
$\mathrm{SnO}_{2}$ nanobelts. The ERS relies on self-thermal reaction of source chemicals to keep the reaction going and get the product. For example, in our experiment, $\mathrm{SnO}_{2}$ powders, $\mathrm{CuO}$ powders, and $\mathrm{Al}$ powders are mixed and put into a reactor at first, and then they are induced to react vigorously, which produces a lot of heat to maintain the reaction system, so that $\mathrm{SnO}_{2}$ nanobelts can be obtained in the process. And characterization and growth mechanism of the obtained $\mathrm{SnO}_{2}$ nanobelts will be discussed in detail.

The ERS is similar to the self-propagating high-temperature synthesis (SHS), though they are actually different. The product obtained by ERS is the soot spurting out of the reactor, while the product obtained by conventional SHS is the solid residue in the reactor. Compared to other methods for the synthesis of $\mathrm{SnO}_{2}$ nanobelts, the ERS has some advantages, such as easiness, high efficiency, convenience, and low cost, so that it can be applied into a vast range of fields.

\section{Experimental Procedures}

Firstly, $\mathrm{SnO}_{2}$ (about $44 \mathrm{~g}, 200$ mesh, $\mathrm{CP}$ ) powders, $\mathrm{CuO}$ (about $6 \mathrm{~g}, 200$ mesh, CP) powders and $\mathrm{Al}$ (about $30 \mathrm{~g}, 200$ 


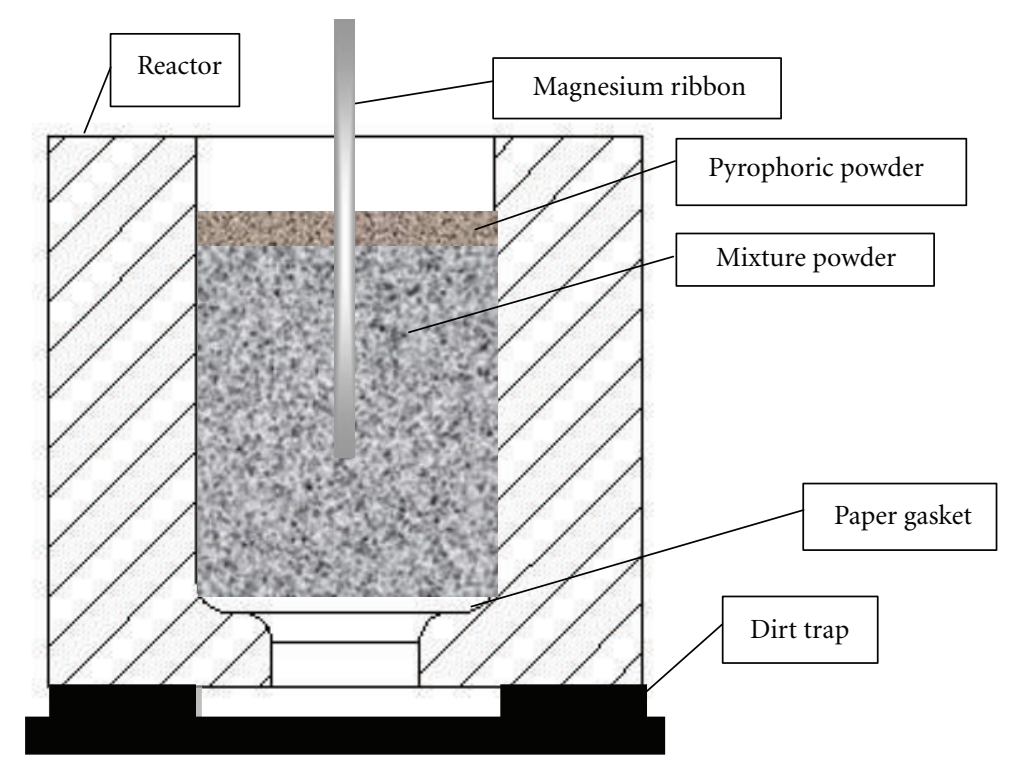

Figure 1: Experimental setup.

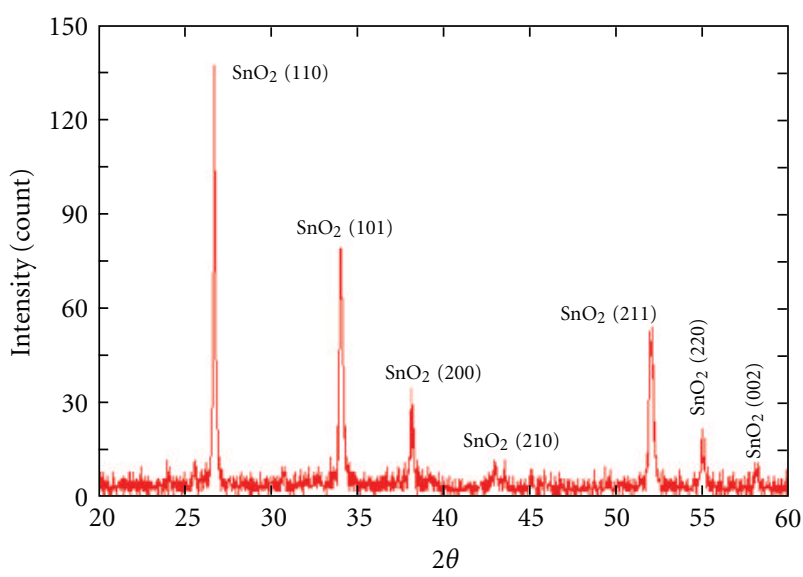

FIGURE 2: XRD pattern of the product synthesized by ERS.

mesh, AR) powders, were mixed and stirred adequately with a mixer and then put into a graphite mold. As shown in Figure 1, at the bottom of the cylindrical graphitic mold was a slight tapering hole covered with a paper gasket beforehand, which was burned in the reaction to let the waste residue from the reaction drip out into the dirttrap. Then a layer of ordinary pyrophoric powders was scattered on the mixture with a magnesium ribbon sticked in it as a primacord. Some more paper gaskets were placed around the mold to collect the product. After the magnesium ribbon was ignited, a cotton-like product sprayed out from the mold and landed on the paper in about 30 seconds.

The product was characterized by X-ray diffraction (XRD; D8 Advanced XRD, Bruker AXS, Germany, with Cu $\mathrm{K}_{\alpha}$ radiation and a normal $\theta-2 \theta$ scan), scanning electron microscopy (SEM; with EDX GENESIS 7000, FEI SIRION,
Netherlands), transmission electron microscopy (TEM; JEOL JEM 2010, Japan, voltage at $200 \mathrm{KV}$ ), high-resolution transmission electron microscopy (HR-TEM; JEOL JEM 2010), and Raman spectroscopy (Renishaw, RM-1000, Ar laser, excitation at $514.5 \mathrm{~nm}$ ).

\section{Results and Discussion}

XRD pattern of the product synthesized by ERS is shown in Figure 2 . There are seven peaks with $2 \theta$ values of $26.72418^{\circ}$, $34.03094^{\circ}, 38.00002^{\circ}, 43.45998^{\circ}, 51.91576^{\circ}, 54.85798^{\circ}$, and $57.87488^{\circ}$, corresponding to $\mathrm{SnO}_{2}$ crystal planes of (110), (101), (200), (210), (211), (220), and (002), respectively. This result matches well with the standard XRD data file of $\mathrm{SnO}_{2}$ (JCPDS-041-1445) [12]. All the diffraction peaks can be indexed to tetragonal rutile structure of $\mathrm{SnO}_{2}$ with lattice constants of $a=b=0.4738 \mathrm{~nm}$ and $c=0.3188 \mathrm{~nm}$. These cliffy diffraction peaks indicate high crystallinity of the $\mathrm{SnO}_{2}$ product obtained in this experiment. In addition, no traces of $\mathrm{Al}$ or $\mathrm{Cu}$ can be detected. The result of energy dispersive $\mathrm{X}$-ray analysis of the $\mathrm{SnO}_{2}$ product is shown in Figure 3. It reveals that the product is made up of O (64.87 at \%), Sn $(29.35$ at \%), and $\mathrm{Al}(5.78$ at \%), which confirms that the product is high-purity $\mathrm{SnO}_{2}$ with little $\mathrm{Al}_{2} \mathrm{O}_{3}$ impurities. Moreover, these $\mathrm{Al}_{2} \mathrm{O}_{3}$ impurities are possible amorphous and trace amounts, so that those cannot be detected by XRD analysis.

SEM image of the $\mathrm{SnO}_{2}$ product is shown in Figure 4. It reveals that the obtained products are a large quantity of wire-like nanostructures with a small number of particles attached to them. The length of these wire-like nanostructures can reach several microns, and radial dimensions of them are no more than $100 \mathrm{~nm}$. These wire-like nanostructures are crooked and disperse, without particular orientation. Their average diameter can be estimated at 


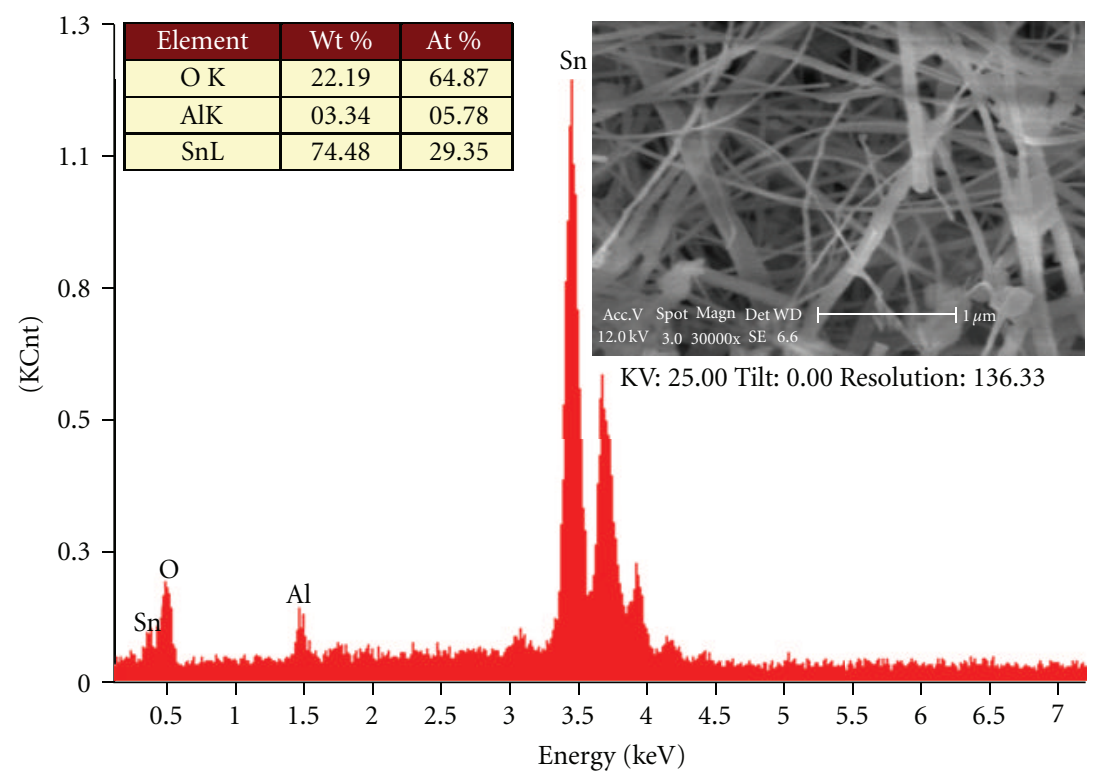

FIGURE 3: Energy dispersive X-ray analysis of the product synthesized by ERS.

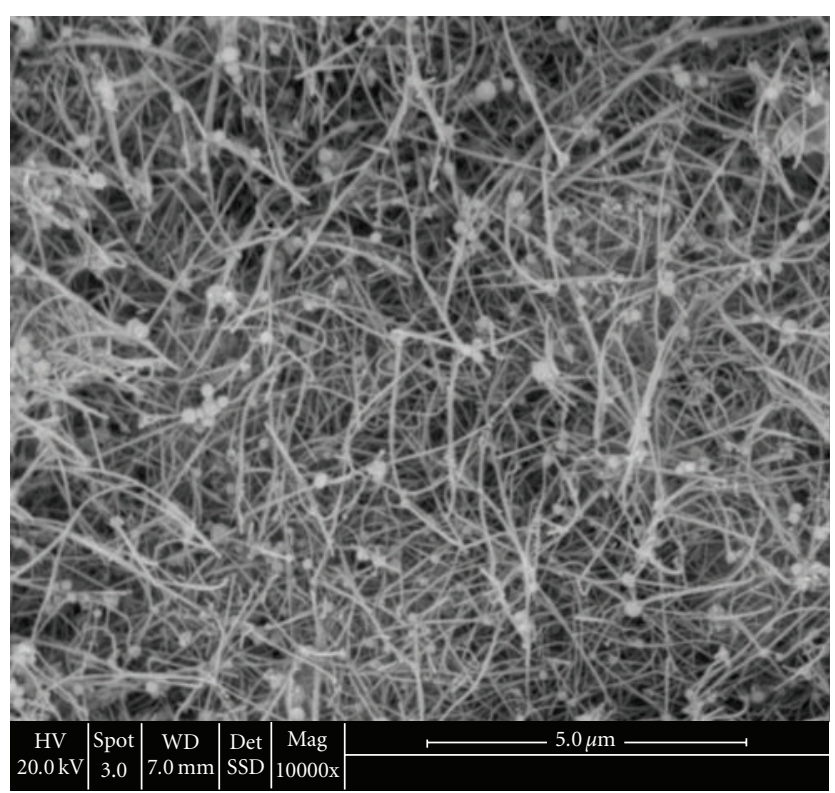

FIGURE 4: SEM image of the $\mathrm{SnO}_{2}$ product synthesized by ERS.

about $50 \mathrm{~nm}$ by using an image zoomer. This result is close to the result of XRD, $70 \mathrm{~nm}$, calculated by Jade5.0.

For a further observation of the individual wire-like nanostructure, some TEM images of the $\mathrm{SnO}_{2}$ product are taken, as they are shown in Figure 5. These TEM images indicate that most of these nanobelts are smooth and uniform along the fiber axis, and typical width, thickness, and length of these nanobelts are in the range of 50-120, 2050 , and $2000-10000 \mathrm{~nm}$, respectively. The statistical results of the number of the nanobelts observed in all the TEM images reveal that the ratio of the nanobelts in the $\mathrm{SnO}_{2}$ products is found to be up to $72 \%$. Figure $5(\mathrm{e})$ shows an individual $\mathrm{SnO}_{2}$ nanobelt and its corresponding selectedarea electron diffraction pattern (SAED, inset in Figure 5(e)). The single set of diffraction spots in the SAED pattern reveals that this belt is a tetragonal single crystal and grows along the (101) orientation, which is in agreement with the previous reports [13]. However, some nanobelts can also be found to grow along the (110) orientation, which verifies that these nanobelts do not grow in one orientation; in other words, preferential growth of these nanobelts did not take place in the crystal growth process. This conclusion can be verified by the HR-TEM image, as is shown in Figure 6. It also demonstrates that the nanobelt is a single crystal with high crystallinity, and its inner structure is highly orderly. Any characteristic imperfects such as big dislocation, twin plane, and subgrain boundary cannot be observed in Figure 6 .

The Raman peaks of the $\mathrm{SnO}_{2}$ nanobelts are detected at 475,633 , and $774 \mathrm{~cm}^{-1}$, corresponding to the $\mathrm{E}_{\mathrm{g}}, \mathrm{A}_{\mathrm{lg}}$, and $\mathrm{B}_{2 \mathrm{~g}}$ vibration modes of standard $\mathrm{SnO}_{2}$ sample, respectively, as are shown in Figure 7. These peaks further verify that these nanobelts are rutile structure $\mathrm{SnO}_{2}$, in accordance with papers reported by Scott [14], Peercy and Morosin [15], and Yu et al. [16]. In fact, widths of these peaks are wider than those of $\mathrm{SnO}_{2}$ nanoparticle [17], which can be explained by the effect of the small dimension of nanobelts.

Based on the experimental data, the mechanism of the ERS of the obtained $\mathrm{SnO}_{2}$ nanobelts can be briefly described by the following reactions:

$$
\begin{gathered}
\mathrm{SnO}_{2(\mathrm{~s})}+\mathrm{Al}_{(\mathrm{s})} \longrightarrow \mathrm{Al}_{2} \mathrm{O}_{3(\mathrm{~s})}+\mathrm{Sn}_{(\mathrm{l})}+\mathrm{Q}_{1}, \\
\mathrm{CuO}_{(\mathrm{s})}+\mathrm{Al}_{(\mathrm{s})} \longrightarrow \mathrm{Al}_{2} \mathrm{O}_{3(\mathrm{~s})}+\mathrm{Cu}_{(\mathrm{s})}+\mathrm{Q}_{2}, \\
\mathrm{Sn}_{(\mathrm{l})}+\mathrm{O}_{2}+\mathrm{Q}_{1}+\mathrm{Q}_{2} \longrightarrow \mathrm{SnO}_{2(\mathrm{~s})} .
\end{gathered}
$$




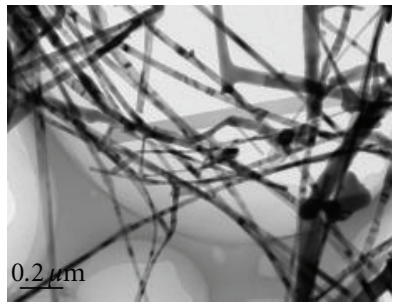

(a)

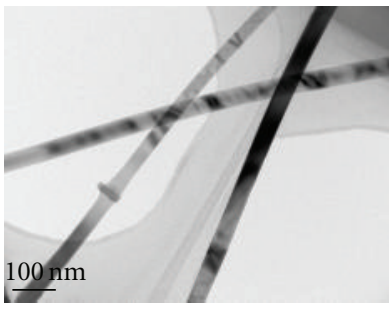

(c)

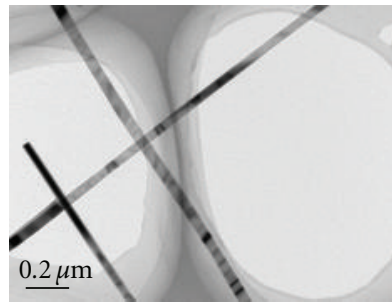

(b)

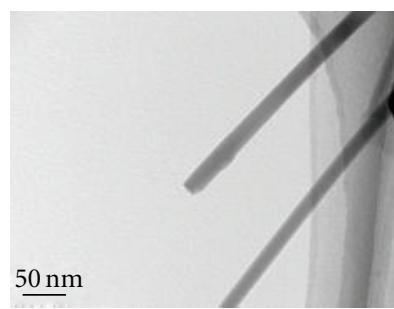

(d)

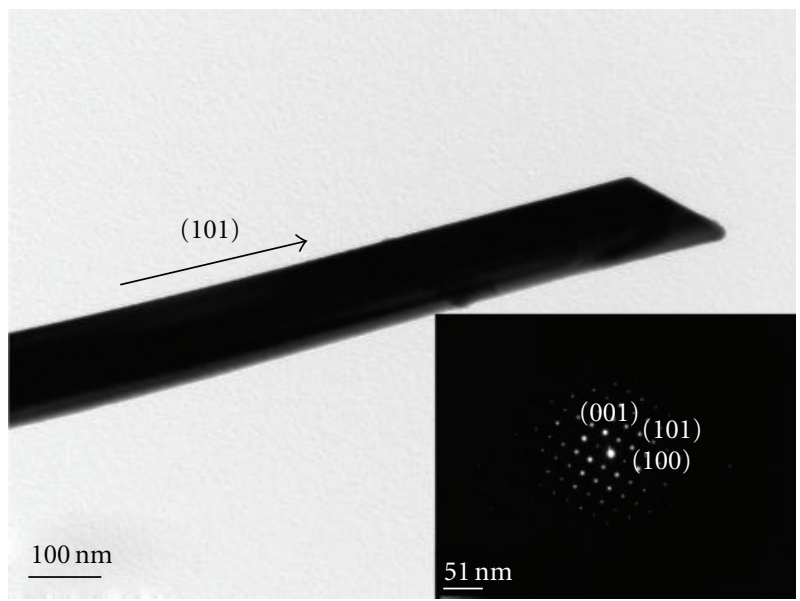

(e)

Figure 5: TEM images of the $\mathrm{SnO}_{2}$ nanobelts. The inset is the selected-area electron diffraction pattern taken from a section of the nanobelt beside it.

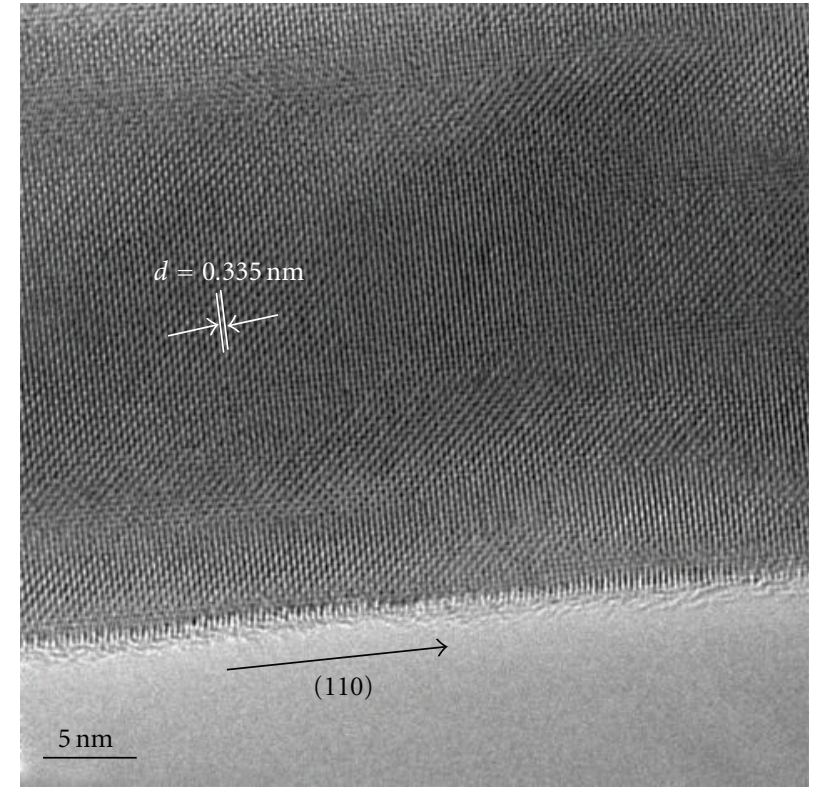

FIGURE 6: HR-TEM image of the $\mathrm{SnO}_{2}$ nanobelts synthesized by ERS.

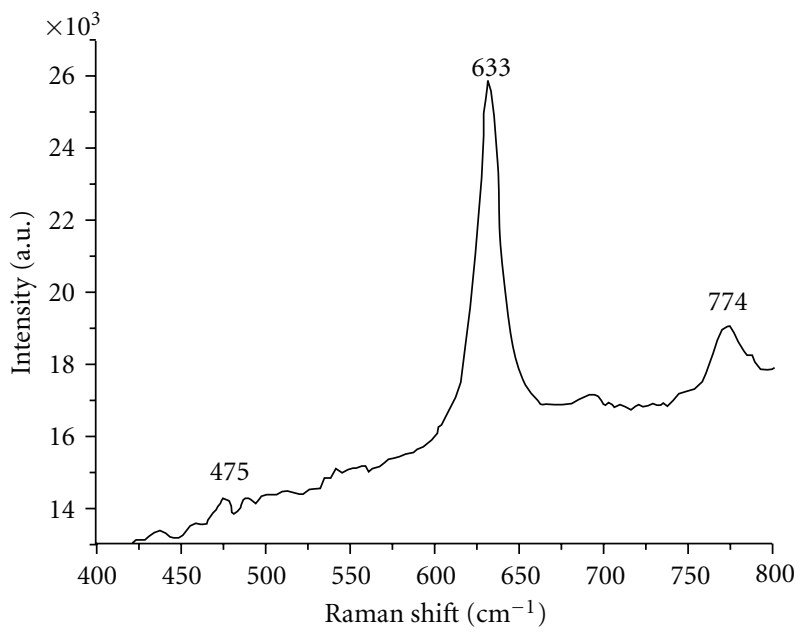

FIGURE 7: Raman spectrum of $\mathrm{SnO}_{2}$ nanobelts synthesized by ERS.

\section{Conclusions}

A convenient and fast method with inexpensive experimental equipment has been developed to synthesize $\mathrm{SnO}_{2}$ nanobelts. The number ratio of the nanobelts in the product is as high as $72 \%$ (others are particle or fiber). The as-grown $\mathrm{SnO}_{2}$ nanobelts have a width of 50-120 nm, thickness of 20-50 nm, and length of $2-10 \mu \mathrm{m}$. The results from XRD pattern, EDX pattern, and Raman spectra indicate that the high-purity $\mathrm{SnO}_{2}$ is single crystal with rutile structure. SAED pattern and HR-TEM image reveal that preferential growth of these nanobelts does not take place in the crystal growth process, and inner structure of the showed nanobelt is highly orderly without characteristic imperfects. A new growth mechanism of the $\mathrm{SnO}_{2}$ nanobelts is also discussed. 


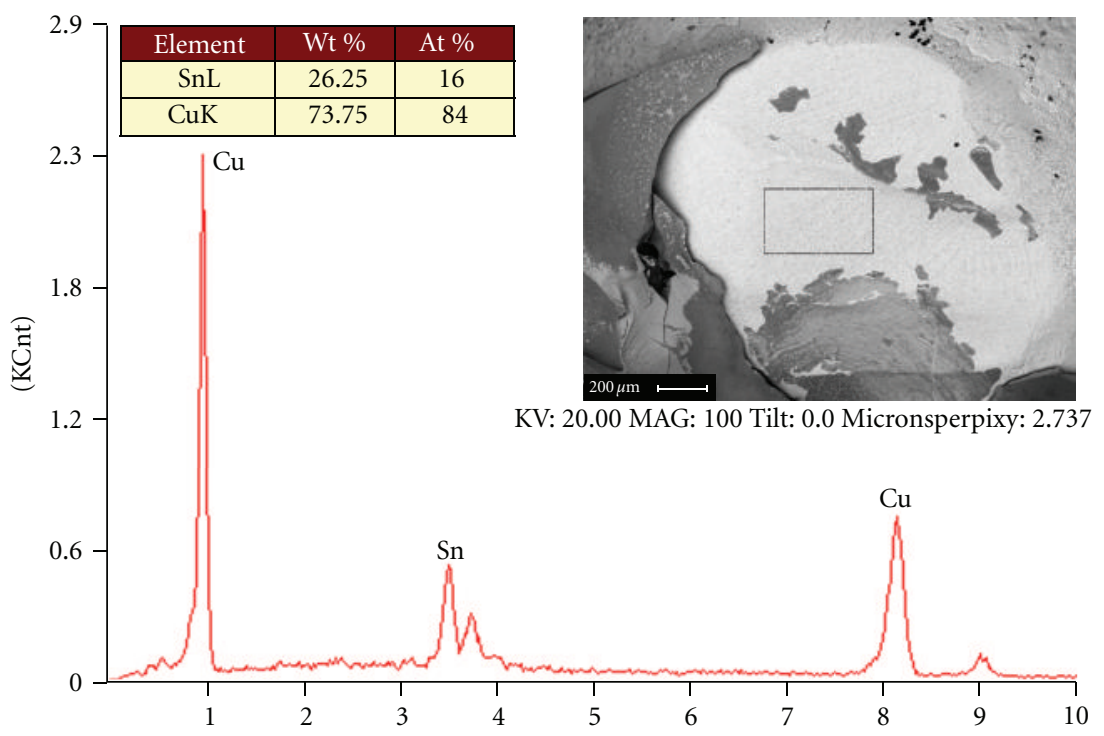

FIgURE 8: Energy dispersive X-ray analysis of upper scrap in the dirt trap.

\section{Acknowledgments}

This work was supported by the Natural Science Foundation of Hubei Province (no. 2009CDB300) and the Fundamental Research Funds for the Central Universities of China (no. 5082001).

\section{References}

[1] Z. W. Pan, Z. R. Dai, and Z. L. Wang, "Nanobelts of semiconducting oxides," Science, vol. 291, no. 5510, pp. 1947-1949, 2001.

[2] O. Lupan, L. Chow, G. Chai, A. Schulte, S. Park, and H. Heinrich, "A rapid hydrothermal synthesis of rutile $\mathrm{SnO}_{2}$ nanowires," Materials Science and Engineering B, vol. 157, no. 1-3, pp. 101-104, 2009.

[3] H. Y. Lu, S. Y. Chu, and S. H. Cheng, "The vibration and photoluminescence properties of one-dimensional $\mathrm{ZnO}$ nanowires," Journal of Crystal Growth, vol. 274, no. 3-4, pp. 506-511, 2005.

[4] Z. W. Pan, Z. R. Dai, and Z. L. Wang, "Lead oxide nanobelts and phase transformation induced by electron beam irradiation," Applied Physics Letters, vol. 80, no. 2, pp. 309-311, 2002.

[5] M. R. Yang, S. Y. Chu, and R. C. Chang, "Synthesis and study of the $\mathrm{SnO}_{2}$ nanowires growth," Sensors and Actuators B, vol. 122, no. 1, pp. 269-273, 2007.

[6] G. Cheng, K. Wu, P. Zhao, Y. Cheng, X. He, and K. Huang, "Solvothermal controlled growth of $\mathrm{Zn}$-doped $\mathrm{SnO}_{2}$ branched nanorod clusters," Journal of Crystal Growth, vol. 309, no. 1, pp. 53-59, 2007.

[7] M. Li, Q. Lu, Y. Nuli, and X. Qian, "Core-shell and hollow microspheres composed of tin oxide nanocrystals as anode materials for lithium-ion batteries," Electrochemical and SolidState Letters, vol. 10, no. 8, pp. K33-K37, 2007.

[8] Z. Q. Liu, D. H. Zhang, S. Han et al., "Laser ablation synthesis and electron transport studies of tin oxide nanowires," Advanced Materials, vol. 15, no. 20, pp. 1754-1757, 2003.
[9] J. X. Wang, D. F. Liu, X. Q. Yan et al., "Growth of $\mathrm{SnO}_{2}$ nanowires with uniform branched structures," Solid State Communications, vol. 130, no. 1-2, pp. 89-94, 2004.

[10] Y. Q. Chen, X. F. Cui, K. Zhang et al., "Bulk-quantity synthesis and self-catalytic VLS growth of $\mathrm{SnO}_{2}$ nanowires by lowertemperature evaporation," Chemical Physics Letters, vol. 369, no. 1-2, pp. 16-20, 2003.

[11] D. Calestani, M. Zha, A. Zappettini et al., "Structural and optical study of $\mathrm{SnO}_{2}$ nanobelts and nanowires," Materials Science and Engineering C, vol. 25, no. 5-8, pp. 625-630, 2005.

[12] Joint Committee on Powder Diffraction Standards, Powder Diffraction (File No. JCPDS-41-1445) (ICSD data).

[13] S. Park, C. Hong, J. Kang, N. Cho, and C. Lee, "Growth of $\mathrm{SnO}_{2}$ nanowires by thermal evaporation on Au-coated $\mathrm{Si}$ substrates," Current Applied Physics, vol. 9, no. 3, pp. S230S233, 2009.

[14] J. F. Scott, "Raman spectrum of $\mathrm{SnO}_{2}$," The Journal of Chemical Physics, vol. 53, no. 2, pp. 852-853, 1970.

[15] P. S. Peercy and B. Morosin, "Pressure and temperature dependences of the Raman-active phonons in $\mathrm{SnO}_{2}$," Physical Review B, vol. 7, no. 6, pp. 2779-2786, 1973.

[16] K. N. Yu, Y. H. Xiong, Y. L. Liu, and C. S. Xiong, "Microstructural change of nano- $\mathrm{SnO}_{2}$ grain assemblages with the annealing temperature," Physical Review B, vol. 55, no. 4, pp. 2666-2671, 1997.

[17] S. Thanasanvorakun, P. Mangkorntong, S. Choopun, and N. Mangkorntong, "Characterization of $\mathrm{SnO}_{2}$ nanowires synthesized from SnO by carbothermal reduction process," Ceramics International, vol. 34, no. 4, pp. 1127-1130, 2008. 

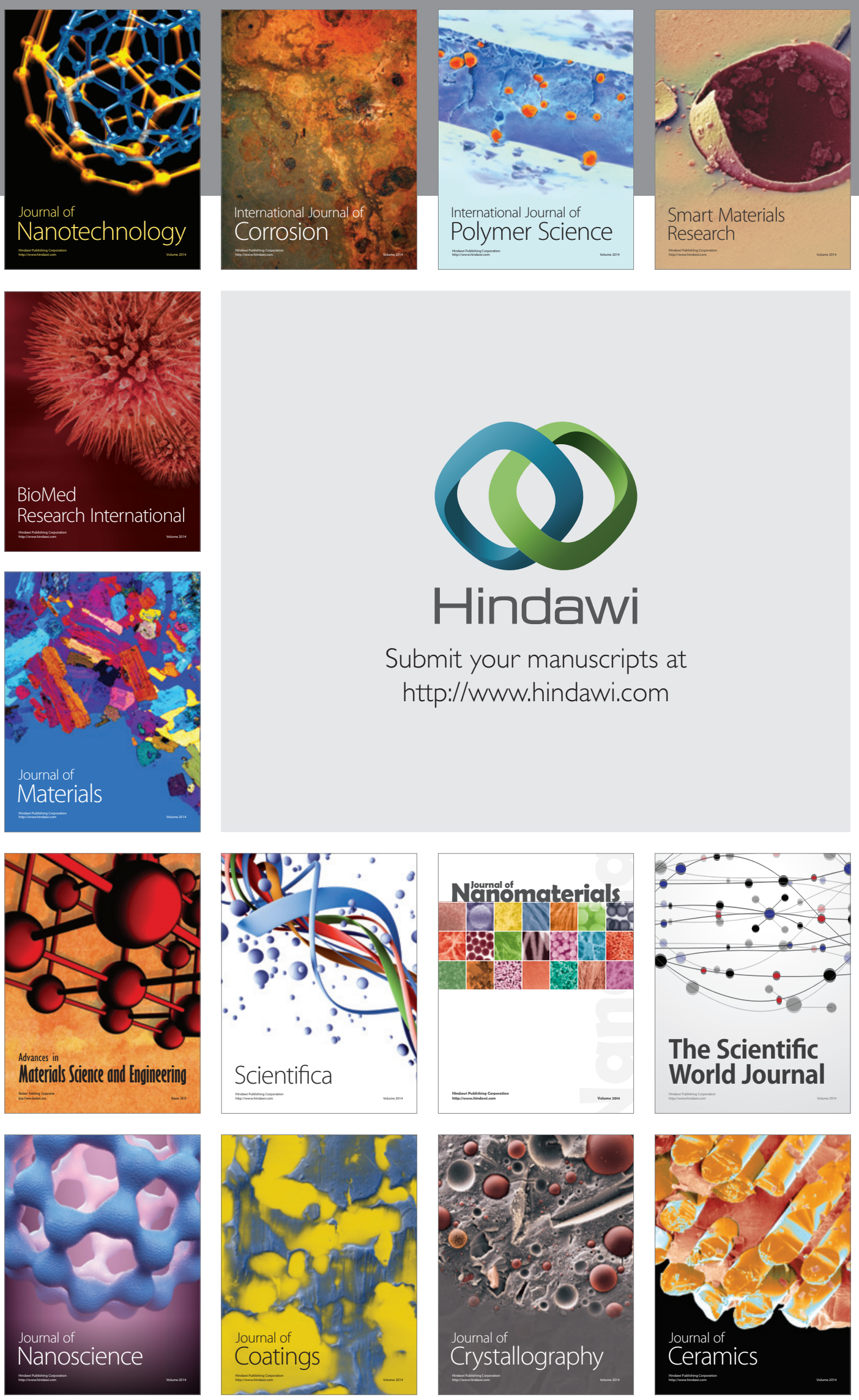

The Scientific World Journal

Submit your manuscripts at

http://www.hindawi.com

\section{World Journal}

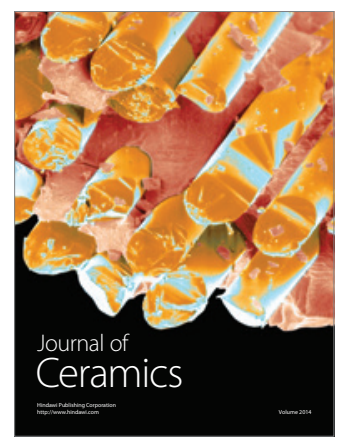

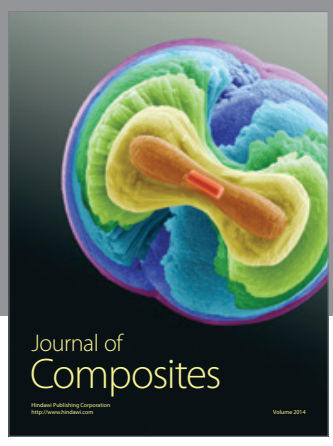
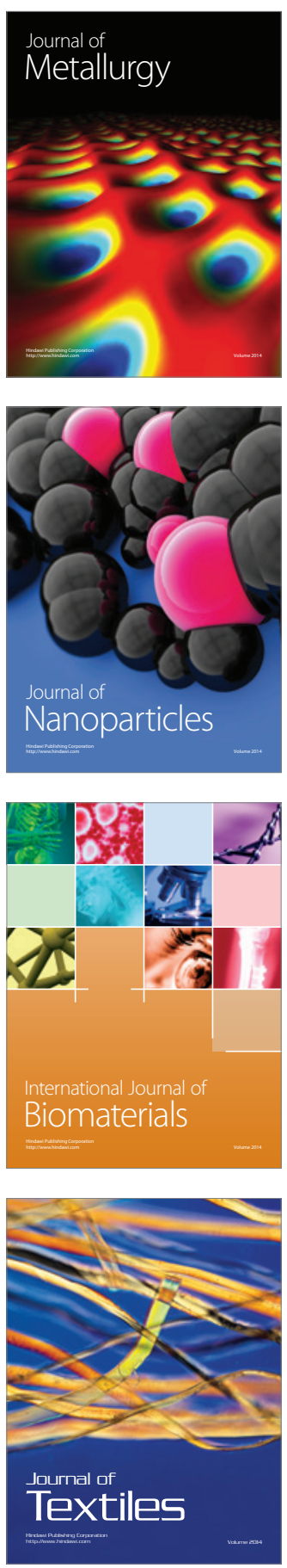